\title{
ATIVIDADES DE RETEXTUALIZAÇÃO DO GÊNERO HISTÓRIA EM QUADRINHOS (HQs): LEITURA \& INTERAÇÃO EM PROCESSO ${ }^{1}$
}

\author{
Francisco Renato Lima (UFPI) ${ }^{2}$
}

\section{RESUMO}

$\mathrm{O}$ ato de ler e escrita implica uma série aspectos, a exemplo da capacidade transformativa do texto, aqui, nesta proposta, entendida como atividades de retextualizações em torno do gênero textual História em Quadrinhos (HQs). Teoricamente, situa-se a partir das contribuições de Costa (2009), Dell'isola (2007), Lima (2019), Matencio (2002), que à luz de Marcuschi (2010 [2001]) desenvolvem estudos aplicando e ampliando os princípios teóricos propostos pelo autor; além de Koch; Elias (2012), Marcuschi (2008) e Saraiva (2001), sobre leitura e produção textual. Objetiva-se analisar duas situações de escrita em que ocorrem a retextualização do gênero HQs. Na primeira, ocorrem operações de transformação do texto-base (HQs), do escrito (verbal) e imagético (não-verbal) para o escrito, com uma alteração parcial na modalidade uso da língua: do escrito e imagético para o puramente escrito; uma mudança de gênero: da HQs para um 'bloco de notas' ou 'comentários', gêneros usuais, tanto no oral, como no escrito; e operações de transformação textual, através de aspectos textuais-discursivos e cognitivos de: i) reformulação, como acréscimo, substituição e reordenação; e de ii) compreensão, como inferência e generalização. Na segunda, atividade de retextualização da HQs houve a produção de um texto de tipologia narrativa, sem gênero definido, mas com estrutura formal clássica: introdução, desenvolvimento e conclusão; além dos elementos constitutivos: narrador, enredo, personagens, espaço e tempo. A partir desse envolvimento entre leitor, o texto e sua produção, percebe-se a retextualização como uma possibilidade de leitura analítica e crítica, que exige a mobilização de uma variedade de conhecimentos implícitos e explícitos, através da articulação de ideias e da interpretação das diferentes nuances interpretativas, imprimindo assim, uma marca de letramento e de leitura em processo, atualizada no ato interativo: produtor, texto e leitor.

Palavras-Chave: Leitura. Retextualização. Gênero textual. História em Quadrinhos (HQs).

\section{ABSTRACT}

The act of reading and writing implies a number of aspects, such as the transformative capacity of the text, here, in this proposal, understood as retextualization activities around the comic book genre. Theoretically, it is based on the contributions of Costa (2009), Dell'isola (2007), Lima (2019), Matencio (2002), who in the light of Marcuschi (2010 [2001]) develop studies applying and expanding the principles theorists proposed by the author; besides Koch; Elias (2012), Marcuschi (2008) and Saraiva (2001), about reading and textual production. The objective is to analyze two writing situations in which there is a retextualization of the comics genre. In the first, there are operations of transformation from the base text (comic books), from the written (verbal) and imagetic (nonverbal) to the written, with a partial change in the use of language: from written and imagetic to the purely written; a change of genre: from comics to a 'notepad' or 'comments', usual genres, both oral and written; and operations of textual transformation through textual-discursive and cognitive aspects of: i) reformulation, such as addition, substitution and reordering; and ii) understanding, such as inference and generalization. In the second, the activity of retextualization of the comics was the

\footnotetext{
1 Trabalho apresentado no Congresso Brasileiro Ciência e Sociedade (CBCS 2019), promovido pelo Centro Universitário Santo Agostinho, de 03 a 05 de outubro de 2019, em Teresina-PI.

${ }^{2}$ Mestre em Letras - Estudos da Linguagem. Atualmente é Professor Substituto, Classe Auxiliar, Nível - I, da Universidade Federal do Piauí (UFPI). E-mail: fcorenatolima@hotmail.com 
ANAIS CBCS 2019 | 3 a 5 de outubro de 2019 | Centro Universitário Santo Agostinho - Teresina - PI

production of a narrative typology text, without a defined genre, but with a formal formal structure: introduction, development and conclusion; beyond the constitutive elements: narrator, plot, characters, space and time. From this involvement between reader, text and its production, retextualization is perceived as a possibility of analytical and critical reading, which requires the mobilization of a variety of implicit and explicit knowledge, through the articulation of ideas and the interpretation of different interpretative nuances, thus imprinting a literacy and reading mark in process, updated in the interactive act: producer, text and reader.

Keywords: Reading. Retextualization. Textual genre. Comics (Comics).

\section{CONSIDERAÇÕES INICIAIS}

A retextualização [...] não é um processo mecânico, já que a passagem da fala para a escrita não se dá naturalmente no plano dos processos de textualização. Trata-se de um

processo que envolve operações complexas que interferem tanto no código como no sentido e evidenciam uma série de aspectos nem sempre bem-compreendidos da relação oralidade-escrita.

(MARCUSCHI, 2010 [2001], p. 46)

As atividades de leitura, compreensão e escrita de textos correspondem ao grande desafio da escola, de promover o acesso aos domínios do mundo letrado, no sentido de promover o acesso e a democratização aos bens culturais que as prática de leitura afortunam socialmente. Nesse sentido, uma habilidade básica é a capacidade de lidar com a maior variedade possível de gêneros textuais, transformando-os, conforme as necessidades comunicativas e as circunstâncias de uso da língua.

Dentre essas possibilidades facultadas pela língua, a retextualização aparece como um caminho frutífero para a ampliação das capacidades cognitivas em leitura e escrita, uma vez que o falante, além de lançar mão de diferentes tipologias e gêneros textuais, nas modalidades oral e escrita da língua, também, imprime expressa seu nível de letramento social, por meio dos usos críticos e reflexivos da língua. Assim é o que ocorre na situação ilustrada neste estudo, quando explora-se possibilidades de retextualização do o gênero textual história em quadrinhos (HQs).

Esse gênero, segundo Costa (2009, p. 126), surgiu há mais de um século nos Estados Unidos, constituído por "uma morfossintaxe e sintaxe discursivas específicas: o desenho, o requadro 
ANAIS CBCS 2019 | 3 a 5 de outubro de 2019 | Centro Universitário Santo Agostinho - Teresina - P

(contorno do quadrinho ou vinheta), o balão, a figura, o uso de onomatopeias e de legendas, a elipse, a página ou prancha, conjugando discurso verbal e pictografias", na construção de uma narrativa, de leitura interativa, criativa, dinâmica, manuseável e portátil.

Partindo desse caráter interativo e funcional do gênero é que, neste estudo, apresenta-se uma proposta de retextualização de um HQ protagonizado pela personagem "Radical Chic". Entende-se esse processo textual-discursivo e interativo à luz das reflexões introdutórias de Marcuschi (2010 [2001]), combinadas aos desenvolvimentos propostos por Dell'isola (2007), Matencio (2002) e Lima (2019); além de Marcuschi (2008), Koch; Elias (2012) e Saraiva (2001), que tratam sobre leitura e escrita.

\section{LEITURA E RETEXTUALIZAÇÃO COMO PROCESSOS DE INTERAÇÃO}

As possibilidades de leitura não se esgotam no que a escrita traz, mas vai além: os sujeitos criam e recriam os objetos da leitura, através de processos que consistem, pois, em reinventar a linguagem por meio da experiência, do vivido, buscando através da subjetividade, desafiar, crescer, ir além das evidências linguísticas, contextualizando e refletindo sobre o objeto cognoscível, e como resultado desta interação social, produzir novos textos (KOCH; ELIAS, 2012).

Nessa perspectiva, saber ler e escrever vai além do domínio de um instrumento, de uma ação mecânica. É uma ação social, integrada às práticas comunicativas, em que o sujeito traz para a leitura as vivências de seu cotidiano. Ao entrar em contato com o conhecimento novo, ele amplia suas percepções de mundo, modificando suas ações do cotidiano, através de práticas significativas de leitura, pois a leitura abre portas para uma compreensão de mundo e criticidade de articulação de ideias no exercício da cidadania, em uma sociedade cada vez mais marcada por práticas de leitura e escrita com significado e significância social. Complementa Saraiva (2001, p. 31) “a leitura constróise, assim, através de atividades de uso, contextualizadas e significativas da linguagem oral e escrita, bem como de atividades e análise e reflexão em condição de interlocução".

Essa leitura ocorre por meio do contato com o texto, que segundo Marcuschi (2008, p. 72), caracteriza-se como ferramenta de fins comunicativos, portanto, além dos aspectos linguísticos, é 
ANAIS CBCS 2019 | 3 a 5 de outubro de 2019 | Centro Universitário Santo Agostinho - Teresina - PI

preciso considerar sua funcionalidade comunicativa, uma vez que ele "é o resultado de uma ação linguística cujas fronteiras são em geral definidas por seus veículos com o mundo no qual ele surge e funciona". Essa funcionalidade é posta em serviço, justamente no processo de retextualização dos gêneros textuais.

[...] partindo-se do princípio de que os gêneros são fenômenos históricos que se relacionam a aspectos culturais e que a língua é manifestação do discurso na enunciação e decorrência das ações do homem em suas interações sociais, considera-se que o processo de retextualização (ou refacção e reescrita) de gêneros textuais traz à tona a necessidade de se refletir sobre a situação de produção de texto como parte integrante do gênero e também sobre as esferas de atividades em que os gêneros se constituem e atuam. (DELL'ISOLA, 2007, p. 12)

Em leitura interpretativa recente de atividades de retextualização, Lima (2019, p. 253) acrescenta que:

As retextualizações não acontecem em um contexto vazio ou neutro ideologicamente, pelo contrário, estão impregnadas da cultura ideológica da escrita (e dos problemas que ela acarreta) e das concepções de mundo dos sujeitos que lidam com as produções textuais. [...] A realização desses processos é um campo fértil ainda, para o estabelecimento do continuum tipológico oral e escrito, visto que há uma mescla, e, ao mesmo tempo, uma reorganização cognitiva dos usos da linguagem, conforme os propósitos discursivos do gênero e as intenções de cada sujeito na produção de (re) construção do texto.

Nesse universo de possibilidades, a retextualização configura um mecanismo de transformação das modalidades textuais e discursivas da língua (DELL'ISOLA, 2007), interferindo na mudança, ou não, na modalidade de uso; ou do gênero, permitindo que o sujeito se insira no mundo da escrita (LIMA, 2019; MATENCIO, 2002), de modo crítico e reflexivo.

\section{A RETEXTUALIZAÇÃO COMO PROPOSTA DE PRODUÇÃO TEXTUAL: UMA BREVE ANÁLISE DO GÊNERO TEXTUAL BALÃO}

O texto em análise ${ }^{3}$ constitui de uma HQs, com a personagem "Radical Chic", publicado no GLOBO, Rio Show, numa sexta-feira, 10 de maio de 2013. A história representa algumas das

\footnotetext{
${ }^{3}$ Essa proposta de análise, semelhante a de Matencio (2002), foi realizada no Ensino Superior, na disciplina Leitura e

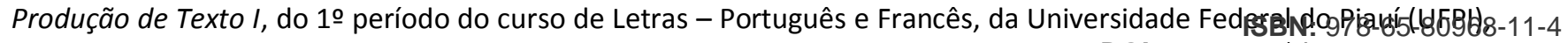


ANAIS CBCS 2019 | 3 a 5 de outubro de 2019 | Centro Universitário Santo Agostinho - Teresina - PI

problemáticas decorrentes das transformações sociais da contemporaneidade. As questões feministas mais evidenciadas são: a produção independente, o desapego ao casamento, a idealização de um parceiro, a dinâmica da rotina familiar versus mercado de trabalho e realização profissional; dentre outras questões relacionadas ao papel ocupado pela mulher na atualidade.

A priori, a HQs aborda uma questão meramente humorística, porém, uma leitura mais minuciosa aponta para questões muito mais amplas, complexas e constituintes da sociedade atual:

\section{Fala/Balão 01:}

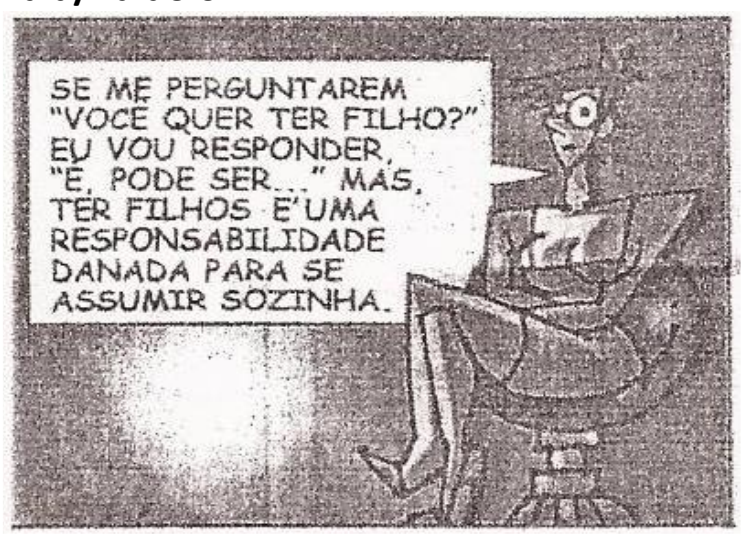

\section{Fala/Balão 02:}

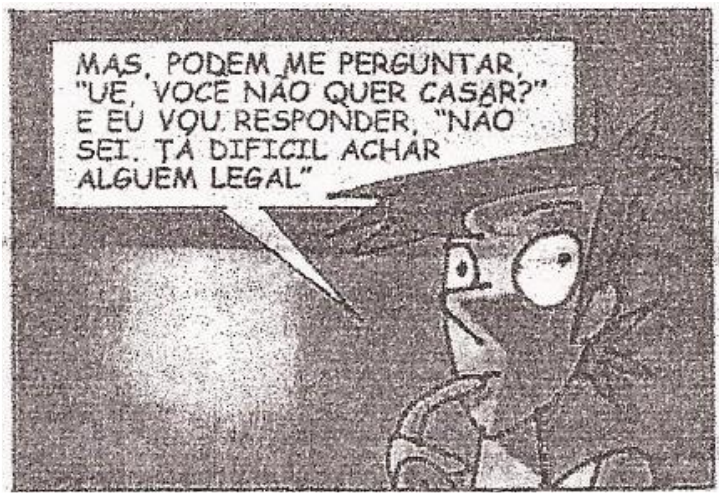

Análise: A personagem se apresenta como uma mulher indecisa diante da possibilidade de ter filhos, partindo do pressuposto de que ter filho é uma tarefa muito difícil de assumir sozinha. Infere-se que ela é uma mulher independente, que não associa a ideia de ter filhos com casamento (produção independente), apesar de que assumir a maternidade sozinha é muito difícil.
Análise: A personagem também repete a postura indecisa diante de uma escolha tão importante na vida: o casamento, alegando que tá difícil encontrar uma pessoa bacana para dividir tais responsabilidades.

semestre 2013.1, ministrada pela professora Dra. Maria Angélica Freire de Carvalho, a quem dispenso agradecimentos. Nesta versão, assumo total responsabilidade sobre o conteúdo apresentado. 
ANAIS CBCS 2019 | 3 a 5 de outubro de 2019 | Centro Universitário Santo Agostinho - Teresina - P

\section{Fala/Balão 03:}

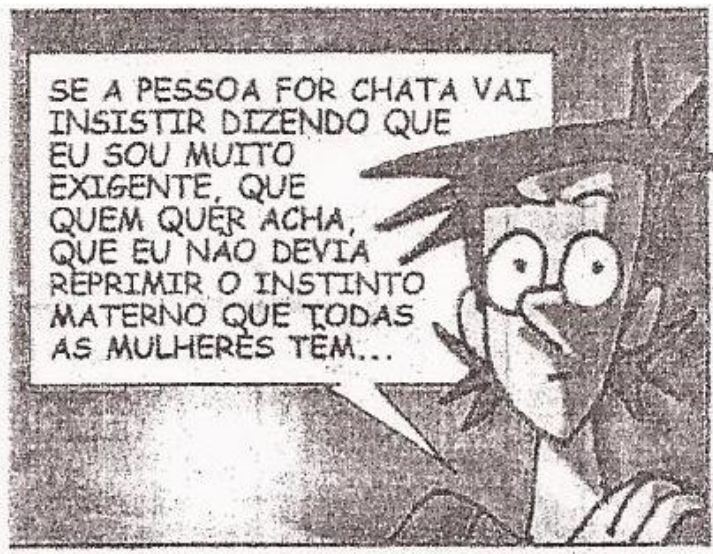

\section{Fala/Balão 04:}

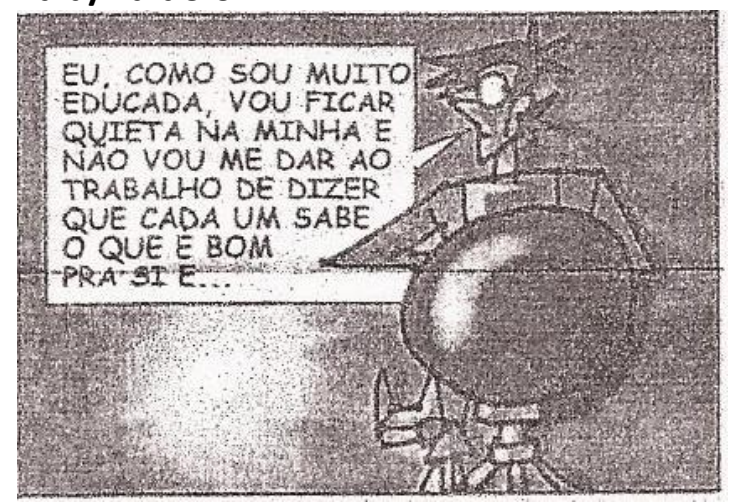

\section{Fala/Balão 05:}

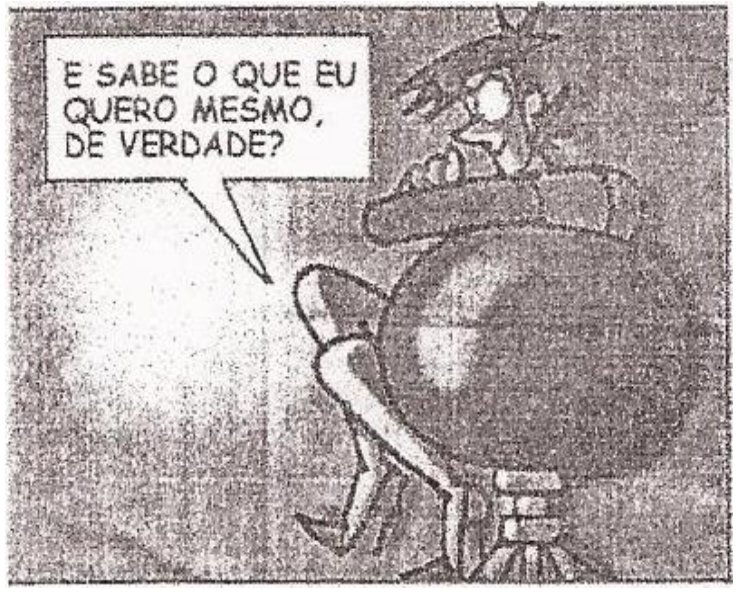

Análise: A personagem é consciente da ideia que as pessoas teriam dela por essas atitudes de incerteza e frente a questões fundamentais a vida de uma mulher. Neste ponto, é possível evidenciar alguns conflitos femininos da sociedade moderna: idealização do parceiro, repressão ao instinto materno em prioridade a outras realizações, realização pessoal $x$ realização profissional, dentre outras comportamentos.
Análise: A personagem aqui tenta parecer educada e segura de seus posicionamentos, mas na verdade ela já busca é um meio para fugir do assunto, não encarar os fatos com segurança e determinação, o que mais uma vez revela seus traços de insegurança em suas escolhas e indecisão em falar sobre as escolhas de sua vida pessoal.
Análise: Como resultado, da estratégia que vem adotando desde a fala anterior, a personagem muda totalmente o foco da discussão e põe um questionamento que será respondido na fala seguinte. Percebe-se que ela consegue mudar o foco da discussão e parte para um assunto superficial, que em nada se assemelha as temáticas casamento e maternidade, fato que também revela outra característica tão recorrente no século XXI: a superficialidade humana. 


\section{Fala/Balão 06:}

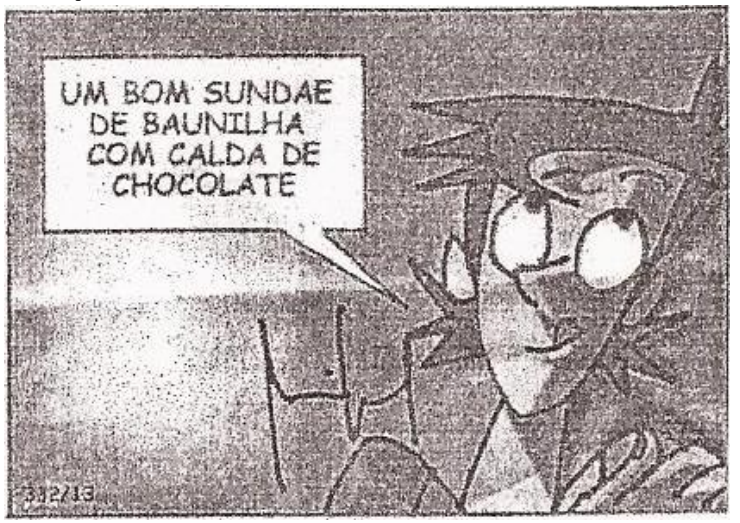

Análise: A personagem conclui que o que deseja mesmo é um "bom sundae de baunilha com calda de chocolate". Concluindo: usou de um artifício de humor para fugir da discussão, reafirmando mais uma vez, as características já evidenciadas durante todo o texto.

Ao lado de cada balão da HQs há uma releitura, ou seja, uma retextualização, feita em caixas de texto. Com base em Marcuschi (2011), veja-se as operações realizadas:

i) transformação do texto-base (HQs): do texto escrito (verbal) e imagético (não-verbal) para o escrito, com uma alteração parcial na modalidade uso da língua: do escrito e imagético para o puramente escrito.

ii) mudança de gênero: da HQs para o que poderia ser chamado de um 'bloco de notas' ou 'comentários', gêneros bastante usuais nesse tipo de atividade, tanto no oral, como no escrito, como identificado por Lima (2019).

iii) operações de transformação do texto, através de aspectos textuais-discursivos e cognitivos de: i) reformulação, como acréscimo, substituição e reordenação do texto; e de ii) compreensão, como inferência e generalização.

O comportamento leitor e a capacidade transformativa, relacionada à competência textual do leitor, nesses processos, evidencia a complexidade que o envolve o papel da escola no compromisso de ensinar a ler e escrever, numa perspectiva de formar sujeitos emancipados intelectualmente, e que, pelo domínio dessas práticas, tornem-se ideologicamente comprometidos com uma cultura da criticidade, da cidadania e da transformação social, ultrapassando os limites impostos por uma visão homogeneizante e inserindo-se no seio da heterogeneidade que constitui a beleza das práticas de linguagem. 
ANAIS CBCS 2019 | 3 a 5 de outubro de 2019 | Centro Universitário Santo Agostinho - Teresina - PI

Uma segunda alternativa de retextualização da HQs foi a produção de um texto de tipologia narrativa, sem gênero definido, mas com estrutura formal clássica: introdução, desenvolvimento e conclusão; além dos elementos constitutivos: narrador, enredo, personagens, espaço e tempo. Veja:

\section{Marisa e os conflitos existenciais de meia idade}

Marisa é uma mulher bem sucedida, administradora de empresa, cerca de 37 anos de idade, mora sozinha em seu apartamento, com seu cachorro Bruce. Tem uma vida totalmente voltada para o trabalho. Suas únicas atividades fixas são o trabalho, academia, o almoço de domingo na casa dos pais, e raramente sai com as amigas pra balada. Quando sai, por muita insistência das amigas, adota uma postura introspectiva, não dança, não bebe, quando alguém mostra interesse por ela, logo coloca algum defeito, diz que a pessoa não faz seu "biotipo", como ela sempre define, enfim; não compartilha realmente dos prazeres da noite, assim como fazem as amigas.

Os pais e as amigas a recriminam por ser tão fechada, dedicar-se tanto ao trabalho $e$ deixar de lado a vida pessoal, insistem que ela saia mais, se divirta, procure se entreter com algum tipo específico de evento, deixe de ser tão exigente e procure conhecer novas pessoas, quem sabe um namorado, novos lugares. Como é muito educada, Marisa escuta a todos os conselhos, rebate-os dizendo que está bem, e quanto a um companheiro, diz sempre que "tá difícil achar alguém legal", mas na verdade é ela que não se permite a isso. É muito exigente, sonhadora e acaba idealizando as pessoas, sendo que estas nunca atendem ao seu padrão.

Apesar de tudo isto, Marisa cogita a possibilidade de ter filhos, quem sabe uma produção independente, mas logo pensa nas responsabilidades que assumirá sozinha. Quando o assunto é casamento, logo argumenta: "tá difícil achar alguém legal", e como é muito insegura e exigente quanto a sua vida pessoal, acaba comprometendo o sonho de ser mãe, pelos riscos que pode enfrentar ao cuidar sozinha de um filho, ou casar-se.

Como resposta a essas recorrentes cobranças vindas de seus pais e de seus amigos, que a querem ver bem resolvidas na vida pessoal e amorosa, Marisa usa sempre uma estratégia de fuga, desconversa do assunto, começa a falar de alguma coisa totalmente contrária, enfim, sai pela tangente, como se diz, e permanece a mesma: indecisa, confusa, exigente, sonhadora, e por isso, até hoje não casou e tão pouco teve filhos.

Fonte: (produção do autor, 2013)

Neste caso, as operações de retextualização utilizadas pelo produtor de texto, envolveram: 


\section{CONQEEESSO CIENCIASSOCIEDADE

ANAIS CBCS 2019 | 3 a 5 de outubro de 2019 | Centro Universitário Santo Agostinho - Teresina - PI

i) transformação do texto-base (HQs): do texto escrito (verbal) e imagético (não-verbal) para o escrito, sem alteração na modalidade uso da língua: do escrito e imagético para o puramente escrito.

ii) mudança de gênero: da HQs para um texto narrativo clássico, que assemelha-se a um conto ou uma crônica narrativa.

iii) operações de transformação do texto, através de aspectos textuais-discursivos e cognitivos de: i) idealização: como eliminação e completude; ii) reformulação, como acréscimo, substituição e reordenação do texto; e de iii) compreensão, como inferência e generalização.

Fundamental também, para essa nova apresentação do texto, foi o nível de compreensão leitora e criticidade do produtor textual, ao lançar mão de recursos linguísticos que materializem a expressividade do verbal e não verbal, contidos no texto-base. Nesse processo, opera com mecanismos cognitivos de (re) elaboração das intenções do produtor da HQs e assume uma autoria sobre o novo texto, construída a partir dos valores, das crenças e das atitudes letradas.

Desse modo, tem-se uma visão relativamente profunda, acerca da complexidade que envolve os processos de escrita e reescrita textual, chamando a atenção então, da escola para o compromisso de ensinar a ler e escrever, numa perspectiva de formar sujeitos emancipados intelectualmente, e que, pelo domínio dessas práticas de produção textual, tornem-se ideologicamente comprometidos com uma cultura da criticidade, da cidadania e da transformação social, ultrapassando os limites impostos por uma visão homogeneizante e inserindo-se no seio da heterogeneidade que constitui a beleza das práticas de linguagem.

\section{CONSIDERAÇÕES FINAIS}

São muitos os temas possíveis de discussão a partir da leitura do HQs. A história apresentase através de um monólogo, em uma estrutura linear (começo, meio e fim), típica das narrativas das HQs, escritas como a intenção de entreter leitores de periódicos, como jornais ou revistas. É um 


\section{CONGBESSO CIENCIAESOCIEDADE

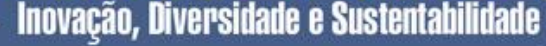

ANAIS CBCS 2019 | 3 a 5 de outubro de 2019 | Centro Universitário Santo Agostinho - Teresina - P

texto bem interessante, de leitura dinâmica, atrativa e com linguagem de fácil compreensão, sendo indicado tanto para adolescentes como adultos.

Sobre as atividades de retextualizações, pode-se perceber que autor, em sua leitura analítica e crítica, identifica uma variedade de conhecimentos implícitos e explícitos, através da articulação de ideias e da interpretação das diferentes nuances interpretativas que o texto aborda.

De tal modo, percebe-se o texto como um espaço de possibilidades de múltiplos 'dizeres', que se concretizam a partir do olhar do leitor, que por meio da interação e dos conhecimentos diversos que possui, imprime um marca de letramento e leitura em processo, realizada no percurso entre o produtor do texto base, a materialidade textual e os conhecimentos do leitor.

\section{REFERÊNCIAS}

COSTA, Sérgio Roberto. Dicionário de gêneros textuais. 2. ed. Belo Horizonte: Autêntica, 2009.

DELL'ISOLA, Regina Lúcia Péret. Retextualização de gêneros escritos. Rio de Janeiro: Lucerna, 2007.

$\mathrm{KOCH}$, Villaça Ingedore; ELIAS, Vanda Maria. Ler e escrever: estratégias de produção textual. 2. ed. São Paulo: Contexto, 2012.

LIMA, Francisco Renato. Letramentos e retextualização em contextos de consulta médica: um estudo sobre a compreensão na relação médico-paciente. Campinas: Mercado de Letras, 2019.

MARCUSCHI, Luiz Antônio. Produção textual, análise de gêneros e compreensão. São Paulo: Parábola, 2008.

MARCUSCHI, Luiz Antônio. Da fala para a escrita: atividades de retextualização. 10. ed. São Paulo: Cortez, 2010. [2001].

MATENCIO, Maria de Lourdes Meirelles. Atividades de retextualização em práticas acadêmicas: um estudo do resumo. Scripta, v. 6, n. 11. Belo Horizonte: PUC Minas, p. 109-122, 2002.

SARAIVA, Juracy Assmann. Literatura e alfabetização: do plano do choro ao plano da ação. Porto Alegre: Artmed, 2001. 